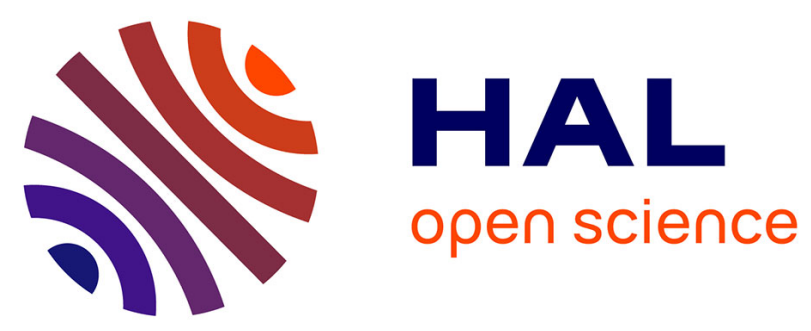

\title{
Reliability and failure analysis of UHF RFID passive tags under thermal storage
}

Sanae Taoufik, Pascal Dherbécourt, Ahmed Eloualkadi, Farid Temcamani

\section{To cite this version:}

Sanae Taoufik, Pascal Dherbécourt, Ahmed Eloualkadi, Farid Temcamani. Reliability and failure analysis of UHF RFID passive tags under thermal storage. IEEE Transactions on Device and Materials Reliability, 2017, 17 (3), pp.531 - 538. 10.1109/TDMR.2017.2733519 . hal-01619293

\section{HAL Id: hal-01619293 https://hal.science/hal-01619293}

Submitted on 19 Oct 2017

HAL is a multi-disciplinary open access archive for the deposit and dissemination of scientific research documents, whether they are published or not. The documents may come from teaching and research institutions in France or abroad, or from public or private research centers.
L'archive ouverte pluridisciplinaire HAL, est destinée au dépôt et à la diffusion de documents scientifiques de niveau recherche, publiés ou non, émanant des établissements d'enseignement et de recherche français ou étrangers, des laboratoires publics ou privés. 


\title{
Reliability and Failure Analysis of UHF RFID Passive Tags under Thermal Storage
}

\author{
Sanae Taoufik, Pascal Dherbécourt, Ahmed El Oualkadi, Farid Temcamani.
}

\begin{abstract}
This paper proposes to study the effects of thermal storage on the reliability of passive UHF RFID tags. Two types of tags M1 and M2 from two different manufacturers are aged under two high temperatures equal to $413 \mathrm{~K}$ and $433 \mathrm{~K}$. Tested tags are put into a thermal storage oven hang fixed terms. The performances of these tags are measured after each aging phase to determine the power loss caused by the high temperature storage. Then a mathematical approach is used to estimate for both tags from the two manufacturers the law of reliability under nominal conditions. Statistical and physical analyses of the results allow us to study and analyze the mechanisms of aging. It is observed that the failure mechanisms depend on the type of passive tags and the values of selected storage temperatures for the tests. The scale parameters of M1 tags aged at $413 \mathrm{~K}$ are around 280 hours, whereas the scale parameters of the M2 tags aged at same temperature are around 360 hours. Cracks on the antenna are observed with the higher temperature equal to $433 \mathrm{~K}$ for M1 tags. However, the changes of the performance of others tags are probably caused by changes in the matching of the impedance between the antenna and the RFIC. From this study, various failure mechanisms demonstrate the necessity of determining the type of passive tags and the used temperature.
\end{abstract}

Index Terms - Accelerated life testing, Failure analysis, Passive radio frequency identification tags, Reliability, RFID, Thermal storage.

\section{INTRODUCTION}

Radio-Frequency IDentification (RFID) is the most important and famous non-contact systems [1]. It is based on data exchange between a transmitter and receiver by the way of electromagnetic signals. RFID technology is used in diverse domains for various applications, because of its flexibility and ability to track and identify persons and objects. RFID is used in healthcare in sensor nets to detect the environment $[2,3]$, it also used in logistics and security, which it is important to track and identify products aiming to guarantee quality and

S. Taoufik Author is with the Laboratory of Information Technology and Communication ,National School of Applied Sciences of Tangier. University Abdelmalek Essaadi Tétouan, Maroc, and she is with Normandie Université, UNIROUEN, INSA Rouen, CNRS, Groupe de Physique des Matériaux, UMR 6634, Avenue de l'université B.P 1276801 Saint Etienne du Rouvray, France (sanae.taou@gmail.com).

P. Dherbécourt is with Normandie Université, UNIROUEN, INSA Rouen, CNRS, Groupe de Physique des Matériaux, UMR 6634, Avenue de l'université B.P 1276801 Saint Etienne du Rouvray, France (pascal.dherbecourt@univ-rouen.fr).

A. El Oualkadi is with the Laboratory of Information Technology and Communication , National School of Applied Sciences of Tangier. University Abdelmalek Essaadi Tétouan, Maroc (eloualkadi@gmail.com).

F. Temcamani is with Quartz laboratory, ENSEA National School of Electronics and its applications 6 Avenue du Ponceau 95014 Cergy Pontoise, France (Farid.Temcamani@ensea.fr). security during manufacture, distribution and shipment [3].

Moreover, RFID passive tags can potentially be used even more widely in automotive and aerospace [3, 4]. This diversity of use requires RFID tags to be exposed to many severe environmental conditions, which may affect their reliability [4]. This makes reliability studies crucial. Accelerated Life Tests (ALTs) are used to demonstrate and test the level of reliability of electronic components under harsh environmental conditions [5, 6]. Considering ALTs, components are subjected to environmental stress amplified compared to the operational use values to accelerate the occurrence of failures [5]. However, the control of failure mechanisms is necessary. It is important to be sure that the failure mechanisms happening in the high stress levels will be the same in the nominal stress by the good selection of the test parameters for the ALTs [5, 7].

In this context, various temperature and humidity tests are widely used particularly to study the reliability of anisotropic conductive adhesive pastes (ACPs), which is used to attach the Radio Frequency Integrated Circuits (RFIC) on the substrate in an RFID tag [7-10]. The global results reported in these articles show that the three parameters: temperature, long time of test and pressure, affect the reliability of ACP. Moreover, the effect of thermal cycling and humidity on the reliability of RFID tags has been studied in [11-14] at high temperature and humidity levels, as well as variation in these factors, may cause stresses on the structure, and change material parameters. However, fewer ALT results of reliability under thermal storage have been published. The thermal storage tests are the closest to reality. It is typically used to determine the effects of time and temperature. Our approach is to estimate the behavioral characteristics of the RFID passive tags in the normal conditions from accelerated tests.

This paper is structured as follows: Section 2 presents the methodology, the tags under test and the measurement bench. In section 3, we discuss the results of accelerated testing at two temperatures $413 \mathrm{~K}$ and $433 \mathrm{~K}$. Then, we use a mathematical approach to estimate the law of reliability under nominal conditions. In sections 4 and 5 we implement the statistical and physical analyzes of the results in order to study and analyze the mechanisms of aging. Finally, the conclusion is given in section 6 .

\section{Methodology AND TAG UNDER TEST}

\section{A. Proposed Methodology used for tags reliability study}

The effects of high temperatures storage on the reliability of passive tags are studied with ALTs, in order to appear failure modes and determine the failures mechanisms. 
The proposed methodology used for tags reliability study is composed of three essential stages (Figure 1). The first one concerns the choice of the tags, two UHF (Ultra High Frequency) passive and low-cost tags from two different manufacturers noted M1 and M2 were selected (Figure 2). The second step is the definition of test parameters. In fact, the choice of the test temperatures is made after several trials. The starting temperature was set at $373 \mathrm{~K}$ corresponding to an overtaking of $20 \%$ of the maximum value recommended by the manufacturer. At this temperature, no significant degradation is measured. Therefore, we need to increase the temperature to create the first degradation. From these trials, two temperatures, $413 \mathrm{~K}$ and $433 \mathrm{~K}$, are selected. A physical and electrical characterization of the set of tags is necessary to identify them during the tests. Ten tags of each type (M1 and M2) are subjected to two high temperatures equal to $413 \mathrm{~K}$ and $433 \mathrm{~K}$, through an oven, which ensures the stability of the temperature during the aging process.

After each aging phase a characterization of the tags is necessary to evaluate the performance changes of these tags, the measurements of reflected power are performed.

The last step of this methodology concerns failure analysis. To identify the failures mechanisms, the aged tags are inspected using an optical microscope and a Scanning Electron Microscopy (SEM).

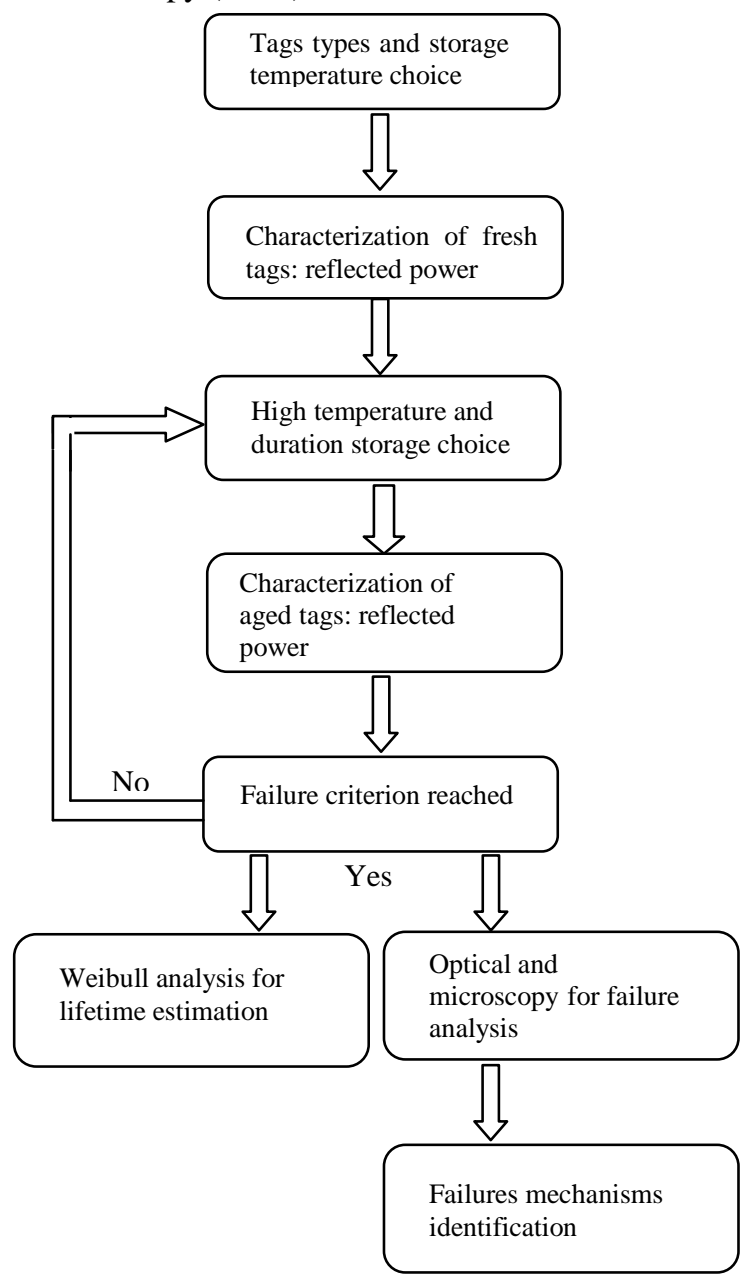

Fig. 1. Methodology of our study.

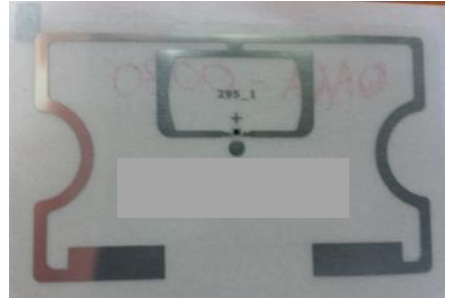

(a)

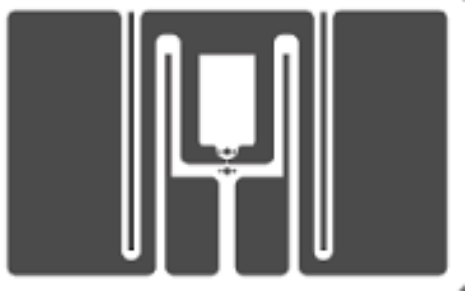

(b)

Fig. 2. Views of the: (a) M1 tag, and (b) M2 tag.

\section{B. Description of tags under test}

Figure 2 shows the photographs of the two types of studied passive tags noted M1 and M2. The sizes of M1 and M2 tags are $40 \mathrm{~mm} \times 54 \mathrm{~mm}$ and $30 \mathrm{~mm} \times 50 \mathrm{~mm}$, respectively. The two tags have both an aluminum antenna connected to an RFIC containing their unique identification code whose memory is 96 bits. The tags use the requirements of EPC Class 1 Generation 2 ISO $18000-6 \mathrm{C}$ [15]. They operate in the $860-960 \mathrm{MHz}$ frequency band and effectively support the temperature between $233 \mathrm{~K}$ and $358 \mathrm{~K}$.

The manufacturing of the $\mathrm{M} 2 \mathrm{tag}$ is based on a production purely paper, different from M1 that use plastic inlay. M2 tags are supplied with a protective paper.

In order to analyze the internal structure of passive tags a transversal cross has been done. The tag to be analyzed is cut and coated with a special resin, and then polished by step more and more finely. Figure 3 shows the microscopic view (x20) of M1 tag.

The chip of each tag is a small RFIC with four gold bumps, one at each corner. The chip size is approximtevely $760 \mu \mathrm{m} \mathrm{x}$ $760 \mu \mathrm{m}$. The gold bumps have a diameter of $65 \mu \mathrm{m}$. The RFIC is attached to the antenna by an anisotropic adhesive pastes (ACP).

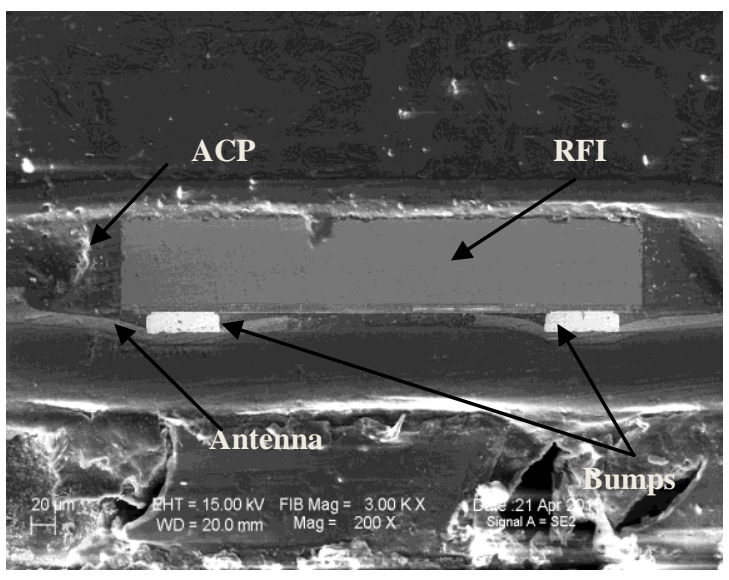

Fig. 3. Cross section of the internal structure of passive M1 tag. 


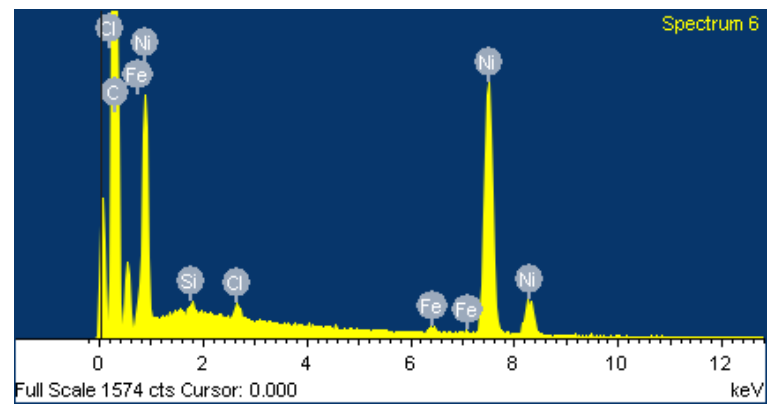

Fig. 4. Energy Dispersive X-ray Spectroscopy of the ACP.

TABLE 1. Details of THE ACP ELEMENTS.

\begin{tabular}{lcc}
\hline Element & Weight \% & Atomic \% \\
\hline $\mathrm{C}$ & 77.03 & 94.17 \\
$\mathrm{Si}$ & 0.17 & 0.09 \\
$\mathrm{CI}$ & 0.23 & 0.09 \\
$\mathrm{Fe}$ & 0.28 & 0.07 \\
$\mathrm{Ni}$ & 22.28 & 5.57 \\
\hline
\end{tabular}

The ACP is a polymer which is filled with conductive nickel particles. In order to analyze the chemical composition of elements constituting the tag structure, Figure 4 shows results of the Energy Dispersive X-ray Spectroscopy (EDS) of the ACP, which characterizes the elemental composition of the analyzed volume. Table 1 shows the percentages of each element of the APC which we found the nickel with an important value.

\section{EXPERIMENTAL DEVELOPMENT AND POWER REFLECTED MEASUREMENTS}

\section{A. Measurement bench description}

The measurement bench is shown in Figure 5. The PC (hot) controls the commercial reader. Which is connected to an antenna placed on a turntable $360^{\circ}$.

The tested tag is disposed on a support placed on a slide rail for a distance of up to 2 meters. The test bench is placed in an open environment of obstacles; it allows readings of the reflected power as a function of distance. This test bench, corresponding to the European standard, can use four possible frequencies in the UHF band: $866.3 \mathrm{MHz}, 866.9 \mathrm{MHz}$, $867.5 \mathrm{MHz}$ or $865.7 \mathrm{MHz}$, the maximum transmitted power by the reader is $30 \mathrm{dBm}$, the antenna gain is $6 \mathrm{dBi}$ [16].

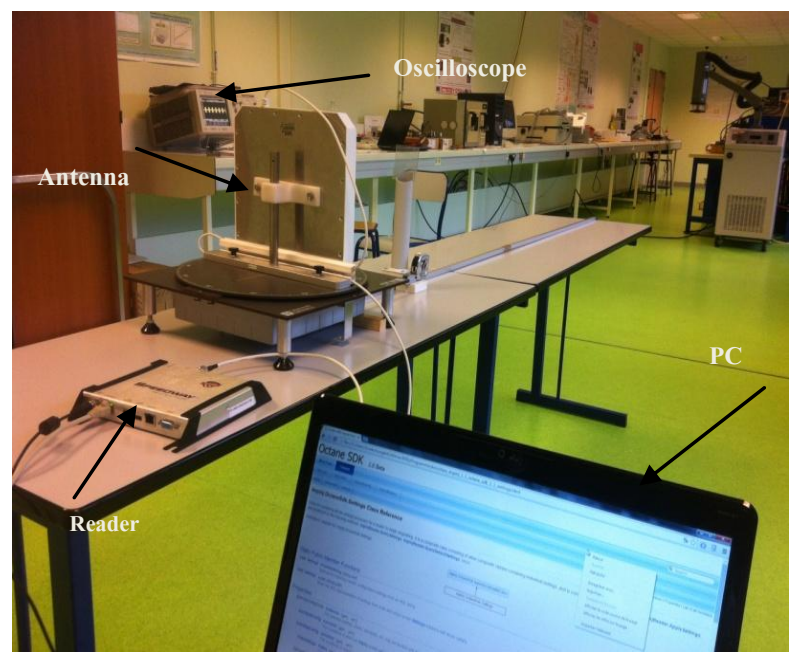

Fig. 5. View of the measurement bench for reflected power measurement.

\section{B. Results and analysis of power reflected measurements}

The reflected power is measured after each aging phase for twenty aged tags, by varying the distance between the reader antenna and the tag. As example of these measurements, Figures 6 and 7 show the obtained results for a M1 tag named W3011 aged at $433 \mathrm{~K}$ and a M2 tag named T3017 aged at $413 \mathrm{~K}$ respectively. The reflected power decreases significantly after each aging phase for all tests.

Altogether ten M2 tags are tested at $413 \mathrm{~K}$ and $433 \mathrm{~K}$. We observe for three of them a premature failure after the first aging test (tree tags aged at $433 \mathrm{~K}$ and one tag aged at $413 \mathrm{~K}$ ).

From these measurements, a mathematical model following a decreasing exponential function is adopted. It represents the

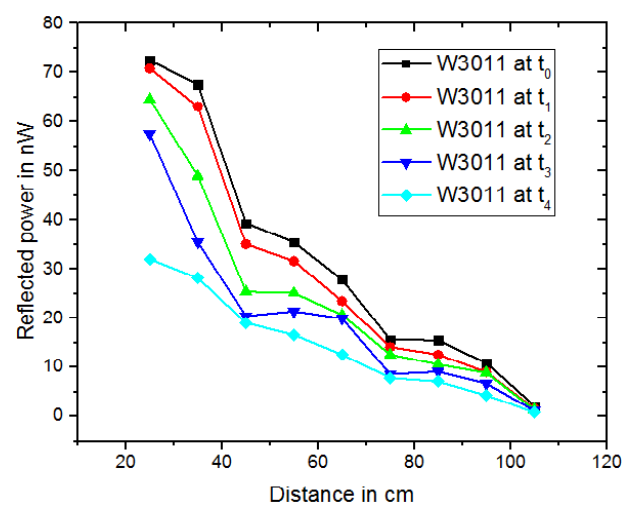

Fig. 6. Reflected power by W3011 aged at $433 \mathrm{~K}$ vs distance. 


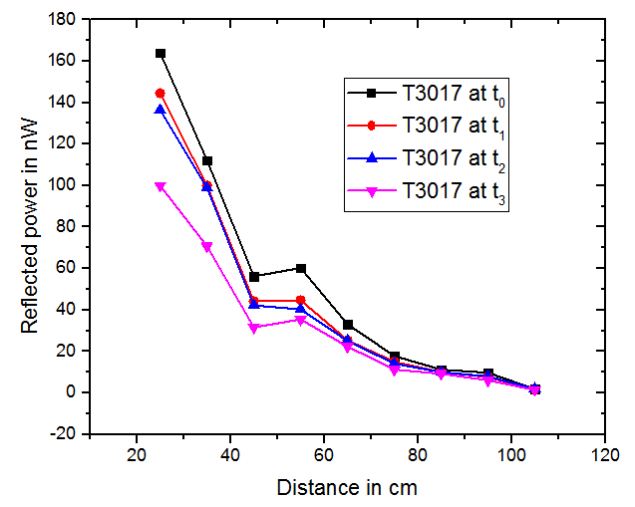

Fig. 7. Reflected power by T3017 aged at $413 \mathrm{~K}$ vs distance.

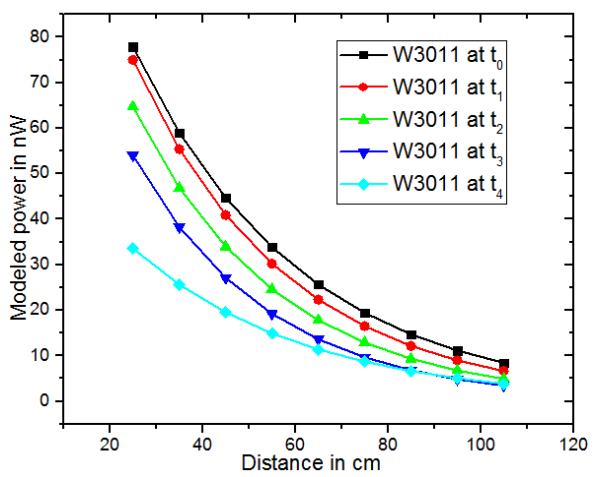

Fig. 8. Modeled reflected power of W3011 aged at $433 \mathrm{~K}$ vs distance.

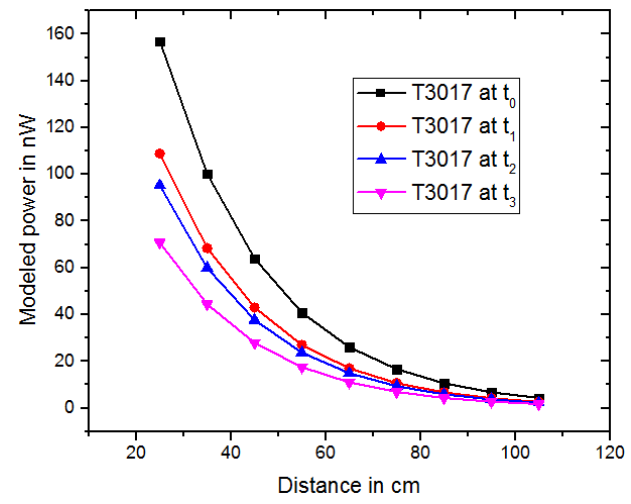

Fig. 9. Modeled reflected power of T3017 aged at $413 \mathrm{~K}$ vs distance.

closest mathematical model to the obtained measurements. After modeling, the plots are presented in Figures 8 and 9.

These curves show the accelerated aging measurements for all aged devices. This model is suitable to estimate the reliability law under nominal conditions. The model is defined with a precise acceleration equation representing the degradation rate according to the selected temperature. At a fixed distance, acceleration equation is giving by:

$$
P_{d}=x T_{v}+y
$$

Where $P_{d}$ is the value of the reflected power at a fixed distance $\mathrm{d}, \mathrm{T}_{\mathrm{v}}$ is the aging time, $x$ represents the straight slope and $y$ is a constant. This coefficient is negative which involves a loss of the reflected power. Figures 10 and 11 show the measurements of the reflected power after modeling for all tested tags, aged at $413 \mathrm{~K}$ and $433 \mathrm{~K}$, a distance $\mathrm{d}=60 \mathrm{~cm}$ for the M1 tags and $\mathrm{d}=40 \mathrm{~cm}$ for the M2. The choice of the

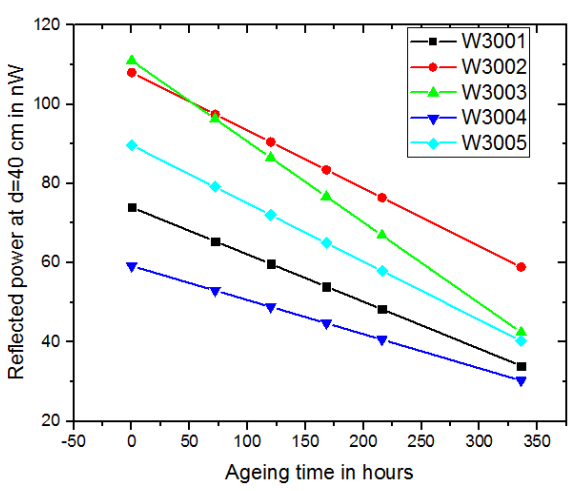

Fig. 10. Reflected power value at $\mathrm{d}=60 \mathrm{~cm}$ of the tags aged at $413 \mathrm{~K}$.

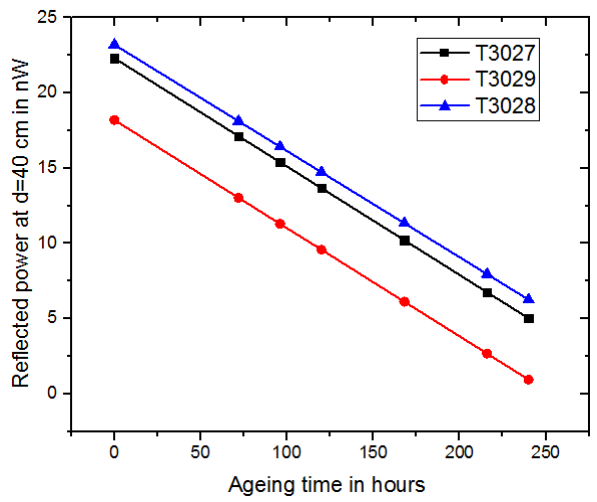

Fig.11. Reflected power value at $\mathrm{d}=40 \mathrm{~cm}$ of the tags aged at $433 \mathrm{~K}$.

measurement distance is suitable with a significant signal power. The same evolution law is observed for different values of distance.

We define the indicator of the lost power at different times $\mathrm{t}_{0}$ (fresh tag, initial value) $\mathrm{t}_{1}, \mathrm{t}_{2} \ldots \mathrm{t}_{\mathrm{i}}$ by:

$$
\Delta P_{d}\left(t_{i}\right)=\frac{\left(P_{d}\left(t_{0}\right)-P_{d}\left(t_{i}\right)\right)}{P_{d}\left(t_{0}\right)}
$$

Where $P_{d}\left(t_{0}\right)$ and $P_{d}\left(t_{i}\right)$ are respectively the values of the reflected power at a fixed distance $d$ of the same tag at $t_{0}=0$ and $t_{\mathrm{i}}$.

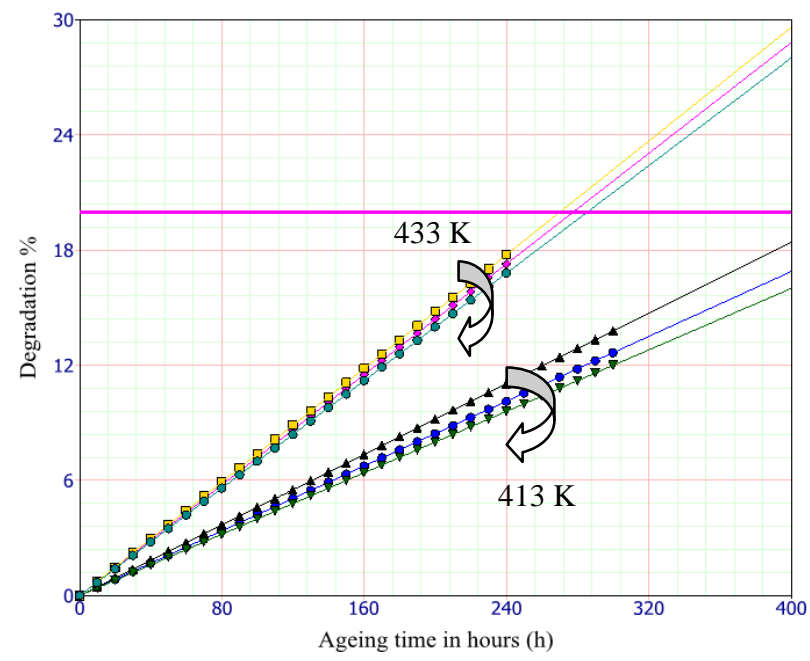

Fig. 12. Degradation of power vs aging time for M1 tags. 


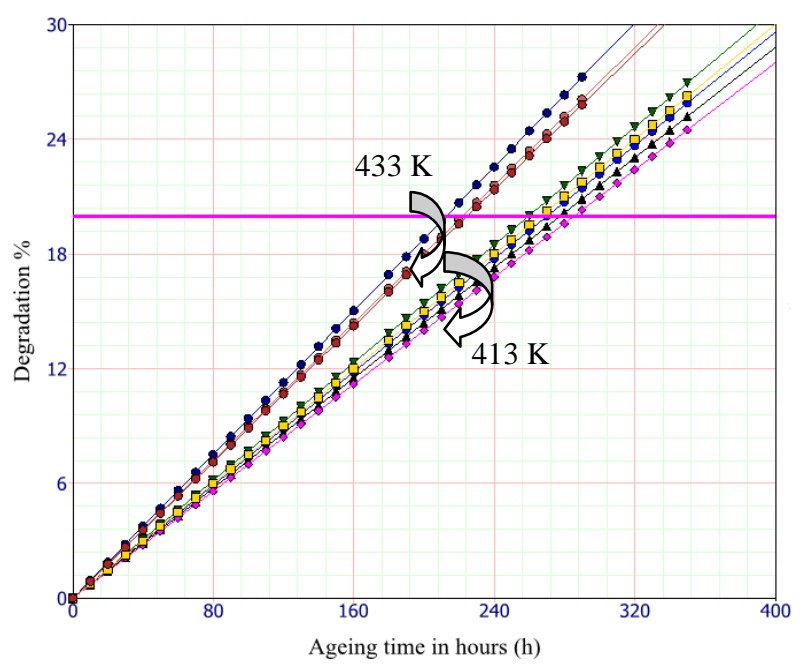

Fig. 13. Degradation of power vs aging time for M2 tags.

In order to analyze the degradation of the power in time, we plot in Figures 12 and 13 the value of this indicator $\Delta \mathrm{P}_{\mathrm{d}}\left(\mathrm{t}_{\mathrm{i}}\right)$ which depends on the aging time for M1 and M2 tags.

Each tag corresponds to a different color. Two graphs are divided into two parts. The first part includes tags aged at $413 \mathrm{~K}$. However, the second represents the set of tags aged at $433 \mathrm{~K}$. The effect of high temperature can be observed by comparing the results from tests at $413 \mathrm{~K}$ and $433 \mathrm{~K}$. The degradation dynamics of reflected power varies for different tags. This expresses the stress acceleration (temperature) applied to each tag. The dynamics of degradation increase with temperature for the M1 and M2 tags.

\section{STATISTICAL ANALYSIS}

Statistical method based on two-parameters Weibull distribution is used in order to study the reliability data statistically. It has been used also to study reliability of ACP connections in various articles $[17,18]$.

The probability density function for the two-parameters Weibull distribution is given by $[19,20]$ :

$$
f(t)=\frac{\beta}{\eta}\left(\frac{t}{\eta}\right)^{\beta-1} e^{-\left(\frac{t}{\eta}\right)^{\beta}}
$$

Where $\eta$ is the scale parameter, it represents the age at which $63 \%$ of the test samples fail, and $\beta$ is a shape parameter represents the kinetics of the failure mechanism, which define the type of degradation phenomenon. With $\beta<1$ the distribution has a failure rate that decreases over time, when $\beta>1$ the failure rate increases over time, and when $\beta=1$ the failure rate is constant [18].

Thermally activated failure mechanisms are modeled using the Arrhenius Equation for acceleration [21]. So to characterize the degradation of tags Arrhenius-Weibull model is chosen. This model describes the acceleration factor based on logarithm of time versus temperature.

The results of thermal storage test given by Weibull plots is shown in Figure 14. These plots provide the probability of failure at one time.

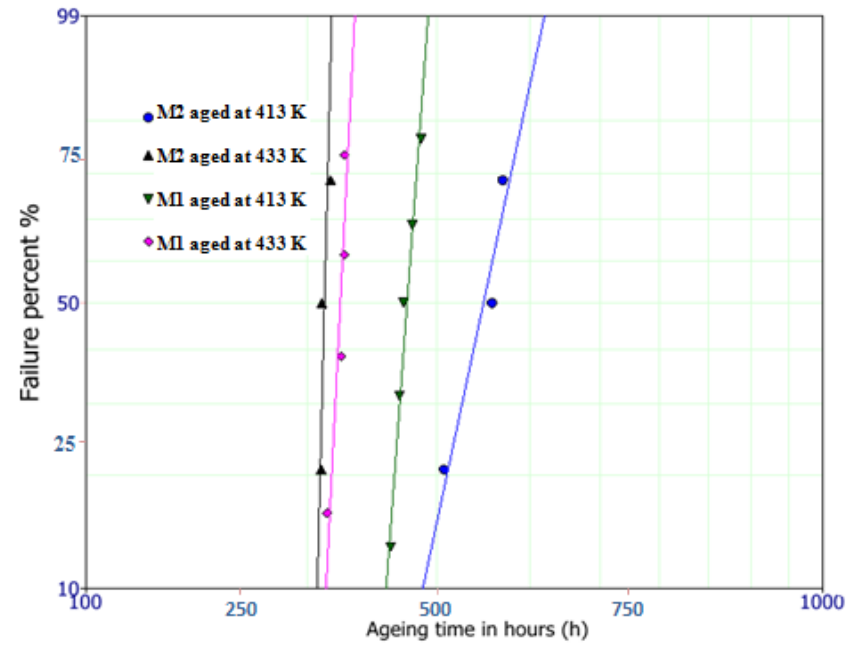

Fig. 14. Weibull probability plots vs aging time.

TABLE 2. SCALE AND SHAPE PARAMETERS OF THE WEIBULL DISTRIBUTIONS.

\begin{tabular}{lcc}
\hline Tests & $\boldsymbol{\beta}$ & $\boldsymbol{\eta}$ \\
\hline M1 aged at 413 K & 40.19 & 276 \\
M1 aged at 433 K & 42.12 & 223 \\
M2 aged at 413 K & 9.9 & 359.7 \\
M2 aged at 433 K & 83 & 211
\end{tabular}

The results of the table 2 and the plots of Figure 14 show a significant difference between the tests. By comparing the scale parameters, it seems that M2 tags are more reliable in this test than M1 tags. The scale parameters of M2 tags aged at $413 \mathrm{~K}$ are around 360 hours, whereas the scale parameters of M1 tags aged at the same temperature are around 280 hours. The obtained results show also a significant difference in the shape parameters of the tests. Different shape parameters may indicate various failure mechanisms.

The plot for the results of M1 tags shows that the lines are parallel, which indicates that we are facing the same failure mechanism.

Another important parameter to calculate is the acceleration factor. This factor can be calculated as a function of temperature by [19]:

$$
A F=e^{B\left(\frac{1}{T_{1}}-\frac{1}{T_{2}}\right)}
$$

Where $T_{1}$ is the temperature for a lifetime $\tau_{1}, T_{2}$ is the temperature for a lifetime $\tau_{2}$ and $B$ is a constant.

Figures 15 and 16 show the plots of acceleration factor as function of temperature for M1 and M2 tags. the acceleration factor is growing from some temperature that shows the limit at which the tags are not qualified and from which the kinetics and mechanism of degradation are revealed. 


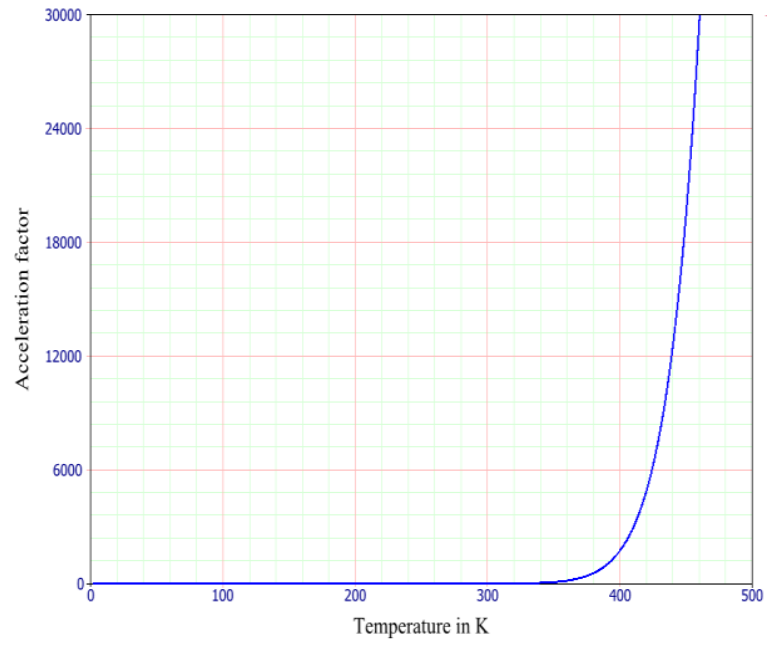

Fig. 15. Acceleration factor vs temperature for M1tags.

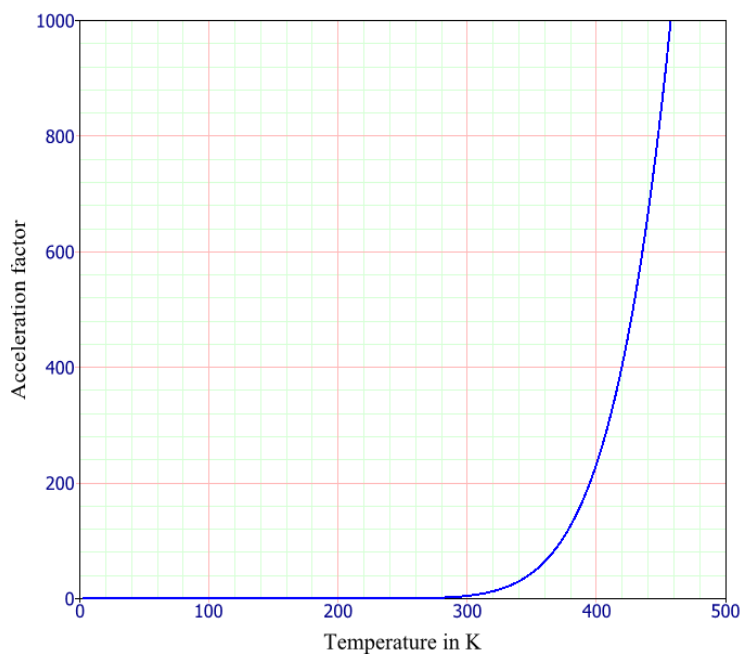

Fig. 16. Acceleration factor vs temperature for M2 tags.

The acceleration factors clearly confirm that tests based on M1 tags accelerated the failures more than did tests based on M2 tags.

\section{FAILURE MECHANISMS}

The performance parameters of the aged tags have been changed significantly after each aging phase; this can be explained by the damage of the antenna or the joints between antenna and RFIC [22].

A few test samples without aging are explored with SEM as reference joints. The obtained SEM micrograph of a joint without failure is given in Figure 17.

After testing, a failure analysis of the samples, using an optical microscope, has revealed cracks on the antennas of the M1 tags tested at $433 \mathrm{~K}$. An example of such cracking is shown in Figure 18-b compared to a fresh tag (Figure 18-a). However, no cracks on the antenna have been observed in the other tags. It is therefore possible that the changes measured in M1 tags during testing at $413 \mathrm{~K}$ and M2 tags were caused by changes in the impedance matching between the RFIC and the antenna caused by changes in the joints, this will vary the performance of the tags $[11,12]$.

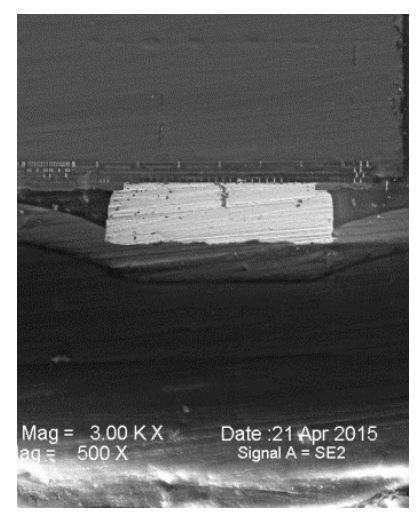

Fig. 17. View of the contact between Antenna/RFIC without failures.

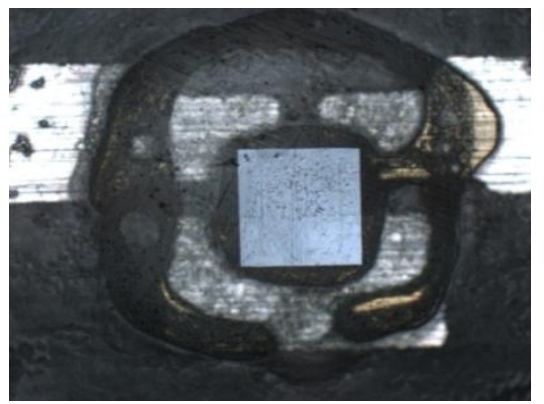

(a)

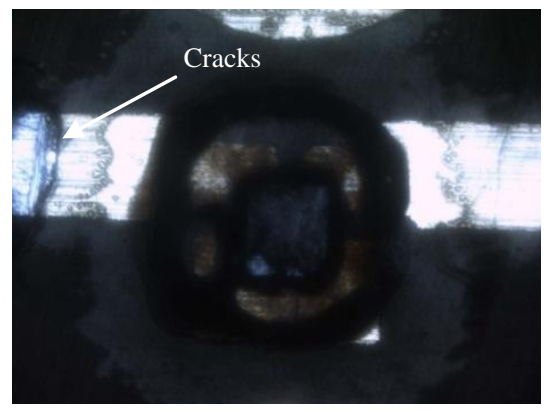

(b)

Fig. 18. (a) Micrograph of a fresh tag, and (b) Micrograph of cracks seen in the antenna.

When cross-sections of the aged tags are achieved and examined using SEM, deformation at the polymer matrix of the ACP was observed. This deformation may dislodge the nickel particles of the ACP in the contact area, this phenomena is also reported by K.Saarinen [11]. In addition, the nickel particles are very small and therefore the contact between the particles and the antenna or the bump is easily disturbed [23]. Figure 19 shows examples of the failed structure for: (a) M1 tag and (b) M2 tag aged at $433 \mathrm{~K}$. 


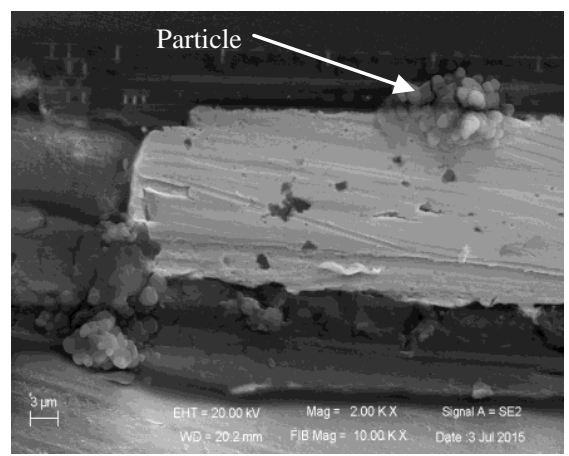

(a)

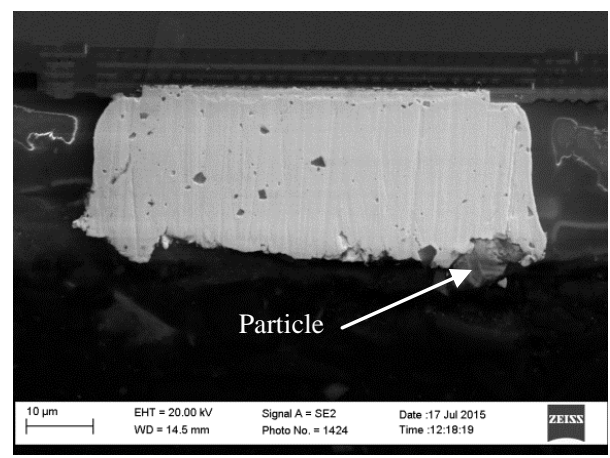

(b)

Fig. 19. Micrograph of deformations observed in the contacts between Antenna/Bump and RFIC/Bump for: (a) M1 tag and (b) M2 tag, aged at $433 \mathrm{~K}$.

This disturbance could change the resistance of the interconnections. Thus result changes in the performance of the aged tags by changing the impedance matching between antenna and the RFIC.

\section{CONCLUSION}

The effects of the high temperature on the performance of passive UHF RFID tags have been studied using two different temperatures on thermal storage test. Two types of UHF passive tags from two different manufacturers have been tested. Using a dedicated measurement bench, the reflected power was measured after each aging phase for all tested tags., The performances decrease significantly after each aging phase with different dynamics of degradation for all aged tags. This dynamics of degradation depends of the temperature test and the type of tag. Clear differences in modes, mechanisms and failure times between M1 and M2 tags have been observed. Two different failure mechanisms have been observed in this study. On a part of the aged tags, cracks in the antenna metallic conductors have been observed. In another part of the tags, no failures in the antenna have been seen, but clear deformations at the polymer matrix of the ACP have been observed, thus changing the impedance matching between the RFIC and the antenna. This study demonstrated the importance of analyzing effects of high temperature using a thermal storage tests, failures occurred significantly faster and cheaper than other types of tests.

Finally, the measurements of the antenna's radiation pattern seem to be an interesting approach to analyze the impact of cracks in the antenna.

\section{REFERENCES}

[1] G. Marrocco, "Pervasive electromagnetics: Sensing paradigms by passive RFID technology," IEEE Wireless Commun., vol. 17, no. 6, pp. 10-17, Dec. 2010

[2] K. Finkenzeller, RFID Handbook: Radio-Frequency Identi cation Fundamentals and Applications, 2nd ed: Wiley, 2004.

[3] K. Domdouzis, B. Kumar, and C. Anumba, "Radio-frequency identification (RFID) applications: A brief introduction," Adv. Eng. Inf., vol. 21 , no. 4 , Oct. 2007.

[4] www.xerafy.com RFID for High Temperatures and Demanding Applications 2017.

[5] E. Suhir, "Accelerated life testing (ALT) in microelectronics and photonics: Its role, attributes, challenges, pitfalls, and interaction with qualification tests," ASME J. Electron. Packag., vol. 124, no. 3, pp. 281291, 2002.

[6] Yang G. Accelerated life tests at higher usage rates. IEEE T Reliab 2005;53:53-7.

[7] Lin YC, Zhong J. A review of the influencing factors on anisotropic conductive adhesives joining technology in electrical applications. J Mater Sci 2008;43:3072-93.

[8] Frisk L, Kokko K. The effects of chip and substrate thickness on the reliability of ACA bonded flip chip joints. Solder Surf Mount Technol 2006;18:28-37.

[9] Seppälä A, Ristolainen E. Study of adhesive flip chip bonding process and failure mechanisms of ACA joint. Microelectron Reliab 2004;44:639-48.

[10] Kim J et al. Thermal degradation of anisotropic conductive film joints under temperature fluctuation. Int J Adhes 2008;28:314-20.

[11] Saarinen K, Frisk L, Ukkonen L. Effect of cycling humidity on the performance of RFID tags with ACA joints. IEEE T Reliab 2012;61:2331.

[12] Saarinen K, Björninen T, Ukkonen L, Frisk L. Reliability analysis of RFID tags in changing humid environment. IEEE Trans Comp Pack 2014;4:77-85.

[13] Lahokallio S, Saarinen-PulliK, FriskL. Effects of different test profiles of temperature cycling tests on the reliability of RFID tags. Microelectron Reliab 2015;55(1):93-100.

[14] Saarinen K, Lahokallio S, Frisk L. Effects of different anisotropically conductive adhesives on the reliability of UHF RFID tags. International Journal of Adhesion \& Adhesives 64(2016) 52-59.

[15] EPCglobal. Overview of the ultra-high frequency (UHF) regulations worldwide. <http://www.gs1.org/epcglobal/implementation> 2017.

[16] S Taoufik, Ahmed El Oualkadi, F Temcamani, B Delacressonniere, P Dherbécourt. Simulation and experimentation of an RFID system in the UHF band for the reliability of passive tags. MedICT, 2015, Saidia, Maroc.

[17] J. Liu and Z. Lau, "Reliability of anisotropically conductive adhesive joints on a flip-chip/FR-4 substrate," J. Electron. Packag., vol. 124, no. 3, pp. 240-245, 2002.

[18] W. Kwon, M. Yim, K. Paik, S. Ham, and S. Lee, "Thermal cycling reliability and delamination of anisotropic conductive adhesives flip chip on organic substrates with emphasis on the thermal deformation," J. Electron. Packag., vol. 127, no. 2, pp. 86-90, 2005.

[19] M. nikulin, L. gerville-reache, V. couallier, Statistiques des essais accélérés, Edition Lavoisier, 2007.

[20] R. Madavan and Sujatha Balaraman, "Failure analysis of transformer liquid - solid insulation system under selective environmental conditions using Weibull statistics method" Engineering Failure Analysis 65 (2016) 26-38.

[21] Shooman, M. Robert, E "Probabilistic Reliability: An Engineering Approach”. Krieger Publishing Compagny, Malabar, Florida. 1990.

[22] Brown WD. Advanced electronic packaging - with emphasis on multi chip modules. New York: IEEEPress; 1999.

[23] Z. Lai and J. Liu, "Anisotropically conductive adhesive flip-chip bonding on rigid and flexible printed circuit substrates," IEEE Transactions on Components, Packaging and Manufacturing Technology, Part B, Vol. 19, No. 3, pp. 644-660, 1996. 